\title{
Right anterior mini-thoracotomy and sutureless valves: the perfect marriage
}

\author{
Marco Solinas ${ }^{1}$, Giacomo Bianchi ${ }^{1}$, Francesca Chiaramonti ${ }^{1}$, Rafik Margaryan ${ }^{1}$, Enkel Kallushi $^{1}$, \\ Tommaso Gasbarri ${ }^{1}$, Filippo Santarelli ${ }^{1}$, Michele Murzi ${ }^{1}$, Pierandrea Farneti ${ }^{1}$, Alessandro Leone ${ }^{1}$, \\ Simone Simeoni ${ }^{1}$, Egidio Varone ${ }^{1}$, Federica Marchi ${ }^{1}$, Mattia Glauber ${ }^{2}$, Giovanni Concistrè ${ }^{1}$ \\ ${ }^{1}$ Department of Adult Cardiac Surgery, G. Pasquinucci Heart Hospital, Fondazione CNR-G. Monasterio, Massa, Italy; ${ }^{2}$ Department of Minimally- \\ Invasive Cardiac Surgery, Istituto Clinico Sant' Ambrogio, Milan, Italy \\ Correspondence to: Giovanni Concistrè. Department of Adult Cardiac Surgery, G. Pasquinucci Heart Hospital, Via Aurelia Sud, 54100 Massa, Italy. \\ Email: gioconci@libero.it.
}

Background: A minimally invasive approach (MIA) reduces mortality and morbidity in patients referred for aortic valve replacement (AVR). Sutureless technology facilitates a MIA. We describe our experience with the sutureless Perceval (LivaNova, Italy) aortic bioprosthesis through a right anterior mini-thoracotomy (RAMT) approach.

Methods: Between March 2011 and October 2019, 1,049 patients underwent AVR with Perceval bioprosthesis. Five hundred and three patients (48\%) were operated through a RAMT approach in the second intercostal space. Considering only isolated AVR (881), 98\% of patients were operated with MIA, and Perceval in RAMT approach was performed in $57 \%$ of these patients. Eight patients (1.6\%) had previously undergone cardiac surgery. The prosthesis sizes implanted were: $S(n=91), M(n=154), L(n=218)$ and XL $(n=40)$. Concomitant procedures were mitral valve surgery $(n=6)$, tricuspid valve repair $(n=1)$, mitral valve repair and tricuspid valve repair $(n=1)$ and miectomy $(n=2)$. Mean age was $78 \pm 4$ years (range, $65-89$ years), 317 patients were female (63\%) and EuroSCORE II was $5.9 \% \pm 8.4 \%$.

Results: The 30-day mortality was $0.8 \%$ (4/503). Cardiopulmonary bypass (CPB) and aortic cross-clamp times were $81.6 \pm 30.8$ and $50.3 \pm 24.5$ minutes respectively for stand-alone procedures. In two patients, early moderate paravalvular leakage appeared as a result of incomplete expansion of the sutureless valve due to oversizing of the bioprosthesis, requiring reoperations at two and nine postoperative days with sutured aortic bioprosthesis implantation. Permanent pacemaker implantation within the first thirty days was necessary in $26(5.2 \%)$ patients. At the mean follow-up of 4.6 years (range, 1 month to 8.6 years), survival was $96 \%$, freedom from reoperation was $99.2 \%$, and mean transvalvular pressure gradient was $11.9 \pm 4.3 \mathrm{mmHg}$.

Conclusions: AVR with the Perceval bioprosthesis in a RAMT approach is a safe and feasible procedure associated with low mortality and excellent hemodynamic performance. Sutureless technology facilitates a RAMT approach.

Keywords: Aortic valve replacement (AVR); biological prosthesis; echocardiography; minimally invasive surgery

Submitted Dec 16, 2019. Accepted for publication Jun 11, 2020.

doi: 10.21037/acs-2019-surd-172

View this article at: http://dx.doi.org/10.21037/acs-2019-surd-172

\section{Introduction}

Open-heart operations with aortic valve replacement (AVR) remains the standard treatment for patients with severe symptomatic aortic valve disease. Transcatheter aortic valve replacement (TAVR) is recommended for patients with high and prohibitive risk for surgical AVR (Class I) or intermediate surgical risk (Class IIa), depending on patient-specific procedural risks, values, and preferences (1). According to the Society of Thoracic Surgeons (STS) 
database, the operative risk of surgical AVR has dramatically improved in the last decade, showing a reduction of mortality from $4.3 \%$ to $2.6 \%$ (2,3). Minimally invasive aortic valve replacement (MIAVR) has evolved into a well-tolerated, efficient surgical treatment option in experienced centres, providing greater patient satisfaction and lower complication rates (4-7). However, MIAVR showed cardiopulmonary bypass (CPB), aortic cross-clamp (ACC) and operative times to be longer than conventional AVR (8). Sutureless aortic bioprosthesis may reduce operative times and make minimally invasive procedures more easily reproducible. Elderly patients and patients with significant comorbidities referred for AVR still have worse outcomes and, therefore, might benefit from sutureless technology through reduced mortality and morbidity (9-13).

The Perceval aortic valve (LivaNova, Italy) is a sutureless bioprosthesis and several reports have shown promising results in terms of mortality, morbidities, hemodynamic performances and, ease of use in performing minimally invasive procedures $(9,11,13)$. The aim of this study was to report early clinical outcomes and mid-term follow-up of the largest single center series of patients undergoing AVR through the right anterior mini-thoracotomy (RAMT) approach with sutureless Perceval bioprosthesis.

\section{Methods}

\section{Patients}

Between March 2011 and October 2019, 1,049 elective patients with symptomatic aortic valve disease underwent AVR with the Perceval sutureless aortic bioprosthesis at Heart Hospital, Massa, Italy. Five hundred and three (48\%) of these patients were operated through the RAMT approach. Considering only isolated AVR [881], 98\% of patients [863] were operated through a minimally invasive approach (MIA) and Perceval in RAMT approach was performed in $58 \%$ of these patients [503]. Baseline patient characteristics are listed in Table 1. In our department, we routinely perform a non-contrast computed tomography (CT) scan of the thorax as preoperative screening to determine the most appropriate surgical approach to AVR for every patient. However, in the last 3 years, we have preferred to perform contrast-enhanced CT scans to better evaluate the characteristics of the native valve and to measure the aortic annulus. Generally, relative dextraposition of the ascending aorta (at least $50 \%$ of the width of the aorta to right of the sternal margin at the

\begin{tabular}{|ll}
\hline Table 1 Baseline patient characteristics & \\
\hline Variables & Overall, $\mathrm{n}=503$ \\
\hline Age, mean \pm SD [range] & $78 \pm 4$ [65-89] \\
\hline Sex, female, [\%] & 317 [63] \\
\hline BSA, mean \pm SD, (m²) & $1.82 \pm 5.3$ \\
\hline Hypertension, [\%] & $364[72]$ \\
\hline Diabetes mellitus, [\%] & $118[23]$ \\
\hline Diabetes on insulin, [\%] & $36[7]$ \\
\hline COPD, [\%] & $65[13]$ \\
\hline Hyperlipidemia, [\%] & $292[58]$ \\
\hline Chronic renal failure on dialysis, [\%] & $6[1]$ \\
\hline Extracardiac arteriopathy, [\%] & $82[16]$ \\
\hline EuroSCORE II, mean \pm SD & $5.9 \pm 8.4$ \\
\hline STS score, mean \pm SD & $4.8 \pm 7.1$ \\
\hline
\end{tabular}

BSA, body surface area; COPD, chronic obstructive pulmonary disease; STS, Society of Thoracic Surgery; SD, standard deviation.

level of the pulmonary trunk bifurcation) and appropriate depth of the aortic root (i.e., not $>10 \mathrm{~cm}$ from skin to the aortic valve annulus) provides optimal surgical exposure for the right minithoracotomy (14). Otherwise, the patient is eligible for upper ministernotomy or full midline sternotomy. However, thanks to the technical improvements of sutureless valve implantation, these criteria are of relative, rather than of absolute importance now. Patient selection for the type of device was left to the discretion of the surgeon. Exclusion criteria for Perceval implantation through a RAMT approach were acute endocarditis, irregular aortic annulus or ascending aorta geometry, isolated aortic regurgitation, bicuspid aortic valve, severe thorax deformities, right pleural cavity adhesions or technical impossibility for peripheral percutaneous venous cannulation. We consider the aortic annulus to be irregular when the three portions of the annulus where the valvular cusps are attached are asymmetrical. The ratio between the diameter of the sinotubular junction and the diameter of the superior annulus should not exceed 1.3 (a ratio $>1.3$ can prevent the correct fixation of the valve-stent on the aorta). Informed consent was obtained from each patient and the study protocol conforms to the ethical guidelines of the 1975 Declaration of Helsinki as reflected in a priori approval by the institution's human research committee. 


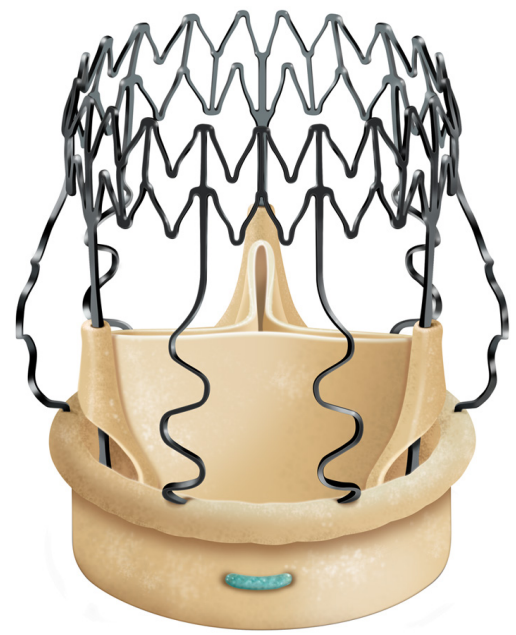

Figure 1 Perceval sutureless bioprosthesis.

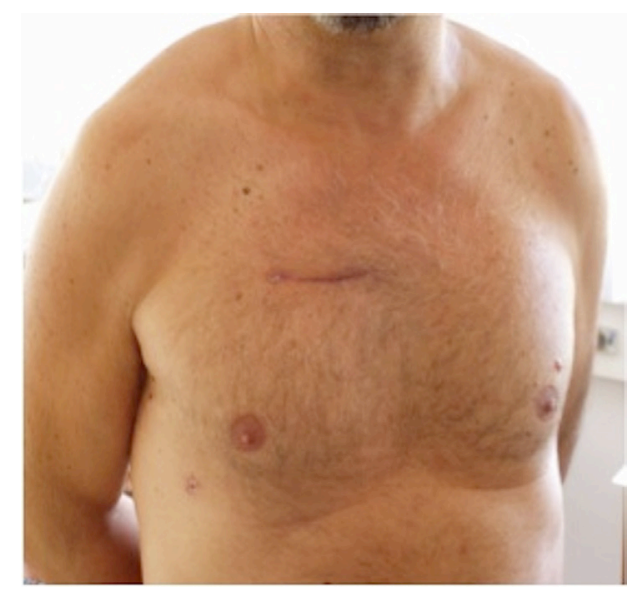

Figure 2 Result of a right anterior minithoracotomy approach.

\section{Technology}

The Perceval aortic valve is a biological prosthesis composed of bovine pericardium mounted within a superelastic alloy frame (Figure 1). This bioprosthesis can be collapsed through a dedicated device and positioned by means of a specific delivery system. The delivery system loaded with the collapsed stent-mounted valve, is guided to its correct position by advancing it over the three guiding sutures (4/0 polypropylene), positioned at the nadir level of each resected cusp. Once the delivery system is in position, the prosthesis is deployed, the guiding sutures are removed and the correct valve position is confirmed. At this point post-dilatation modeling is performed with a dedicated balloon (thirty seconds at a pressure of four atmosphere) while the valve is flushed with warm saline at $37^{\circ} \mathrm{C}$ to optimize final sealing. This sutureless aortic valve prosthesis is available in size $\mathrm{S}, \mathrm{M}, \mathrm{L}$, and XL. The Perceval aortic valve obtained European (CE) approval in February 2011 for size S and M, September 2011 for size L, November 2013 for size XL and U.S. Food and Drug Administration (FDA) approval in January 2016. We instituted oral anticoagulation therapy with warfarin sodium for 3 months after Perceval implantation reaching an international normalized ratio between 2.0 and 3.0. After 3 months, unless another indication for anticoagulation exists, we substitute warfarin with $100 \mathrm{mg}$ of aspirin daily.

\section{Surgical technique}

All surgeries were performed by senior surgeons of our department, with no difference in operative technique, rigorously following a standardised internal protocol. RAMT was performed through an incision $(5-6 \mathrm{~cm})$ in the second intercostal space (Figure 2). In patients with associated mitral and tricuspid procedures, a third intercostal space anterior minithoracotomy was preferred. The rib was always spared. Concomitant procedures are reported in Table 2. A soft tissue retractor was used to open the working field. Direct aortic cannulation was performed using low-profile cannulas. Venous drainage was achieved with a variety of percutaneous venous cannulas inserted through the femoral vein into the venae cavae. The correct placement of the venous cannula was obtained using the Seldinger technique under transoesophageal echocardiographic guidance. Vacuum-assisted venous drainage can facilitate venous return. In our experience, the total negative pressure is maintained at no greater than $-40 \mathrm{mmHg}$. Once vacuum-assisted CPB was established, a left ventricular vent was placed through the right superior pulmonary vein, and the patient was cooled to 34 or $35^{\circ} \mathrm{C}$. The ascending aorta was clamped with the Cygnet crossclamp (Novare Surgical Systems, Cupertino, California). Antegrade cardioplegic solution was delivered into the aortic root or selectively into the coronary ostia using warm blood cardioplegia or cold crystalloid solution (Custodiol Koehler Chemie, Alsbach-Haenlein, Germany). In all cases of RAMT, the surgical field was flooded with carbon dioxide at a flow of $0.5-1.0 \mathrm{l} / \mathrm{min}$. Transverse aortotomy was performed approximately $2 \mathrm{~cm}$ above the commissures and the aortic valve was inspected. The aortic valve leaflets were totally excised and the aortic annulus decalcified. A 


\begin{tabular}{|c|c|}
\hline Variables & Overall, $n=503$ \\
\hline Aortic stenosis, (\%) & $373(74.2)$ \\
\hline Aortic steno-insufficiency, (\%) & $130(25.8)$ \\
\hline \multicolumn{2}{|l|}{ Valve size, (\%) } \\
\hline S & $91(18.1)$ \\
\hline M & $154(30.6)$ \\
\hline L & 218 (43.3) \\
\hline$X L$ & $40(8.0)$ \\
\hline \multicolumn{2}{|l|}{ Combined procedures, (\%) } \\
\hline Mitral valvoplasty & $3(0.6)$ \\
\hline Mitral valve replacement & $3(0.6)$ \\
\hline Tricuspid valve repair & $1(0.2)$ \\
\hline $\begin{array}{l}\text { Mitral valve replacement + } \\
\text { tricuspid valve repair }\end{array}$ & $1(0.2)$ \\
\hline Myectomy & $2(0.4)$ \\
\hline Conversion to full sternotomy, (\%) & $2(0.4)$ \\
\hline Re-intervention, (\%) & $8(1.6)$ \\
\hline \multicolumn{2}{|l|}{ Previous surgery, (\%) } \\
\hline Mitral valve repair & $2(0.4)$ \\
\hline Mitral valve replacement & $1(0.2)$ \\
\hline Aortic valve replacement & $2(0.4)$ \\
\hline Coronary artery bypass grafting & $3(0.6)$ \\
\hline $\begin{array}{l}\text { ACC time for stand-alone procedure, } \\
\text { mean } \pm S D,(\min )\end{array}$ & $50.3 \pm 24.5$ \\
\hline $\begin{array}{l}\text { CPB time for stand-alone procedure, } \\
\text { mean } \pm S D \text {, (min) }\end{array}$ & $81.6 \pm 30.8$ \\
\hline $\begin{array}{l}\text { ACC time with combined procedures } \\
\text { and REDO, mean } \pm S D \text {, (min) }\end{array}$ & $85.2 \pm 28.9$ \\
\hline $\begin{array}{l}\text { CPB time with combined procedures } \\
\text { and REDO, mean } \pm S D \text {, (min) }\end{array}$ & $129.6 \pm 44.8$ \\
\hline
\end{tabular}

ACC, aortic cross-clamp; CPB, cardiopulmonary bypass; REDO, re-interventions; SD, standard deviation.

standard implantation sutureless prosthesis technique was implemented. The aortotomy was closed with a continuous 4-0 polypropylene suture and the patient weaned from CPB. Satisfactory positioning and normal function of the prosthesis were assessed by intraoperative transesophageal echocardiography immediately after weaning from CPB.
At the end of surgery, patients were transferred to the ICU and managed according to the unit protocol.

\section{Study design}

This is a retrospective descriptive single-center study that reports early and mid-term results of a large cohort of patients, selected based on the sutureless bioprosthesis implantation and surgical approach.

\section{Data collection}

Preoperative, intraoperative, and postoperative in-hospital data were collected through a computerized medical record system. The follow-up was obtained from interview with the surviving patients in regard to their postoperative adverse events, actual functional status, and in all examined patients we performed echocardiography. For all patients the first visit was made after 1 month, then 6 months, one year and anually thereafter. Mean follow-up time was 4.6 years (range, 1 month to 8.6 years). Clinical and echocardiographic follow-up of survival patients is $97.6 \%$ complete.

\section{Statistical analysis}

All continuous variables are expressed as mean \pm standard deviation; categorical variables are expressed as percentage. Level of significance was set for $\mathrm{P}<0.05$ to reject the null hypothesis. Survival analysis was performed using KaplanMeyer method. All calculations are made using R statistical package ( $\mathrm{R}$ core team; R Foundation for Statistical Computing, Vienna, Austria).

\section{Results}

All patients had preoperative aortic valve stenosis with or without regurgitation and the preoperative mean pressure gradient were $55.8 \pm 13.1 \mathrm{mmHg}$. The EuroSCORE II and STS score were $5.9 \% \pm 8.4 \%$ and $4.8 \% \pm 7.1 \%$, respectively. Eight patients $(1.6 \%)$ had previously undergone cardiac surgery. Prosthesis sizes implanted were: S ( $\mathrm{n}=91), M$ $(\mathrm{n}=154), \mathrm{L}(\mathrm{n}=218)$ and $\mathrm{XL}(\mathrm{n}=40)$. Concomitant procedures were mitral valve surgery $(n=6)$, tricuspid valve repair $(\mathrm{n}=1)$, mitral valve repair and tricuspid valve repair $(\mathrm{n}=1)$ and myectomy $(\mathrm{n}=2)$. CPB and ACC time were $81.6 \pm 30.8$ minutes and $50.3 \pm 24.5$ minutes for isolated AVR and $129.6 \pm 44.8$ minutes and $85.2 \pm 28.9$ minutes for combined 
procedures and reinterventions (Table 2). Conversion to full sternotomy occurred in one patient for bleeding of the aortic wall at the clamping site and in one patient due to haemodynamic instability, which required coronary artery bypass grafting. One patient was revised for bleeding, through the same approach. The thirty-day mortality was $0.8 \%$ (4/503). One patient died from heart failure which was not prosthesis-related, two patients of stroke and one patient of intestinal ischemia. Mean hospital stay was $6.4 \pm 3.8$ days; $73 \%$ of patients [364] were discharged at home. Seven patients $(1.3 \%)$ developed acute renal failure requiring short-term dialysis. In Figure 3, we report survival, freedom from stroke, from endocarditis and from reintervention analyses. Eleven patients $(2.2 \%)$ had a postoperative stroke, confirmed by computer tomography (Figure 3B). Permanent pacemaker implantation within the first 30 days was necessary in $26(5.2 \%)$ patients (Table 3). Two patients $(0.4 \%)$ developed early moderatesevere paravalvular regurgitation due to incomplete expansion of the sutureless valve due to oversizing of bioprosthesis, requiring the implantation of a sutured bioprosthetic valve on postoperative days 2 and 9. The surgical approach in these two patients was through the same approach.

\section{Mid-term follow-up}

At the mean follow-up of 4.6 years (range, 1 month to 8.6 years), survival was $96 \%$ (Figure $3 A$ ). Four patients $(0.8 \%)$ had stroke (Figure $3 A$ ). Freedom from reoperation was $99.2 \%$ (Figure $3 D$ ). Four patients $(0.8 \%$ ) presented with lung herniation, requiring reoperation by re-approximating the ribs again with non-absorbable sutures. No valve migration or valve thrombosis was observed. Endocarditis occurred in three patients $(0.6 \%)$, requiring reoperation (Figure 3C). Perceval degeneration occurred in 4 patients $(0.8 \%)$ : one patient was treated with sutured bioprosthesis implantation, six years after first implant, and three patients were treated with valve-in-valve procedure and transfemoral bioprosthesis implantation, at four, six, and eight years respectively after the first implant.

Prosthesis function and hemodynamic performance was assessed at discharge and at follow-up. Mean pressure gradient decreased significantly from a preoperative value of $55.8 \pm 13.1$ to $11.9 \pm 4.3 \mathrm{mmHg}$ at follow-up $(\mathrm{P}<0.001)$. $\mathrm{LV}$ mass decreased from 149.8 to $113.6 \mathrm{~g} / \mathrm{m}^{2}(\mathrm{P}<0.001)$. Moderate paravalvular leakage occurred in one patient without hemolysis, not requiring any treatment (Table 4).

\section{Discussion}

This study shows the clinical and echocardiographic results with sutureless aortic bioprosthesis in 503 patients who underwent AVR through the RAMT approach. We demonstrated that the implantation of Perceval bioprosthesis in a RAMT is a safe and feasible procedure associated with low mortality and excellent hemodynamic performance at mid-term follow-up. This study represents the largest single center cohort of patients who were operated through a RAMT approach with Perceval bioprosthesis implantation.

Sutureless bioprostheses represent an innovative approach for surgical AVR that allows faster implantation, reducing CPB and ACC time. This is advantageous for all patients, regardless of the risk profile, including patients at higher risk of complications following cardiac surgery. Furthermore, Perceval is an ideal valve for minimally invasive approaches, because a number of surgical steps such as placing sutures and tying the knots are eliminated, thus facilitating AVR through a small incision. RAMT in AVR was developed in the past few years (15). Prospective randomized studies have shown advantages of the MIA in terms of decreased bleeding, postsurgical pain and trauma, and shorter hospital and intensive care unit stay times, with consequent cost reduction (16-18). Santana et al. concluded that minimally invasive AVR in obese patients has a lower morbidity and mortality when compared with the standard median sternotomy approach (19). Furthermore, minimally invasive aortic valve surgery is associated with improved survival, despite longer myocardial ischaemic times than full sternotomy (20). RAMT is generally considered to be a challenging approach only reserved for expert surgeons, and the main concerns with this approach are a narrow space to work, limited visibility, and the difficulties of managing deviations from the normal course of intervention and intraoperative complications. Previously, our group summarized several criteria for patient eligibility for the RAMT approach (14). With the introduction of the Perceval sutureless valve in our daily practice, these criteria have less importance in patient selection. Provided that no absolute contraindications, such as severe thorax deformities, right pleural cavity adhesions, or unsuitable access for peripheral percutaneous venous cannulation, are present, nearly every patient could be operated on routinely through RAMT for AVR. Minimally invasive AVR is facilitated and essentially enabled with the advent of the sutureless prosthesis. In our experience 30-day mortality 

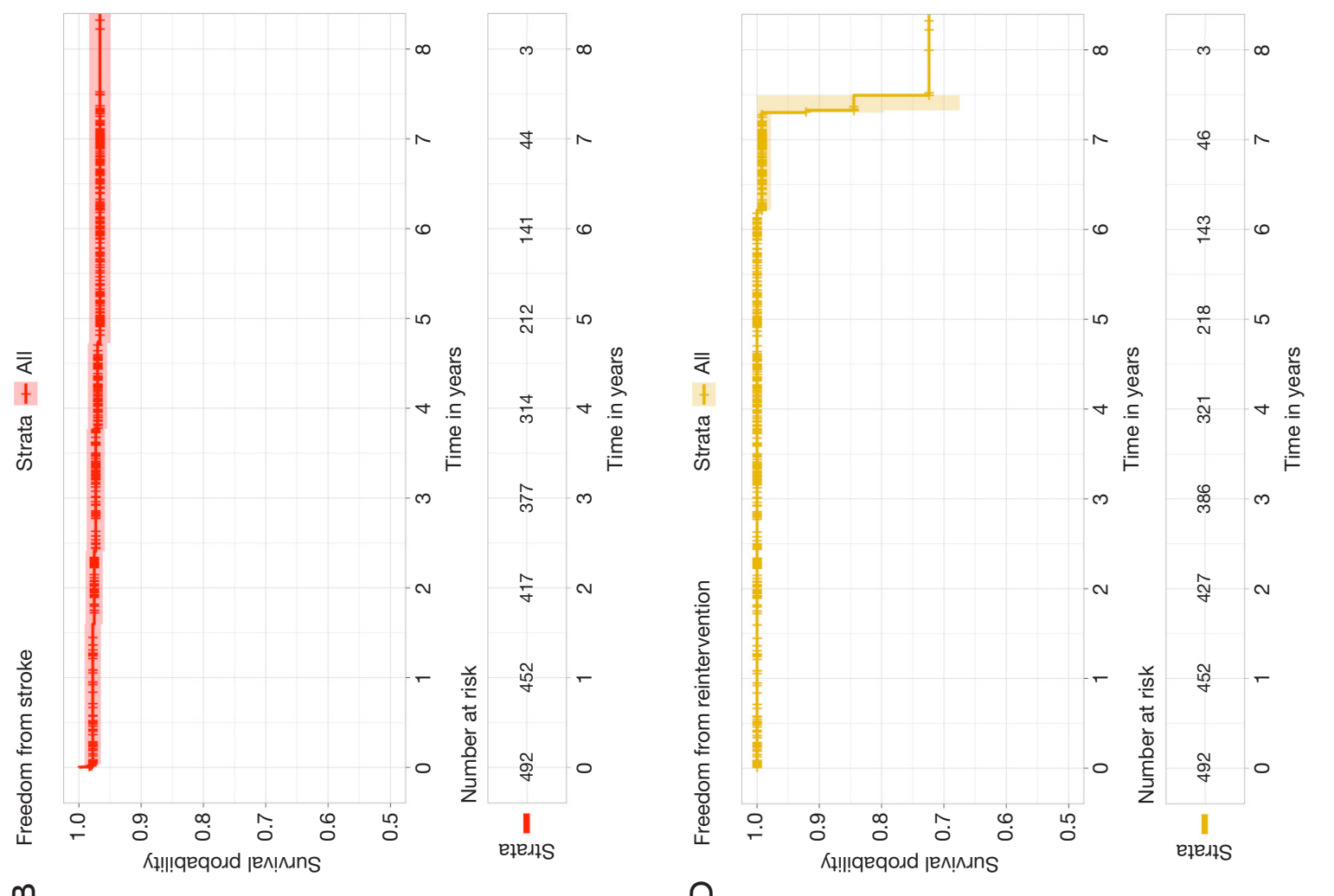

口
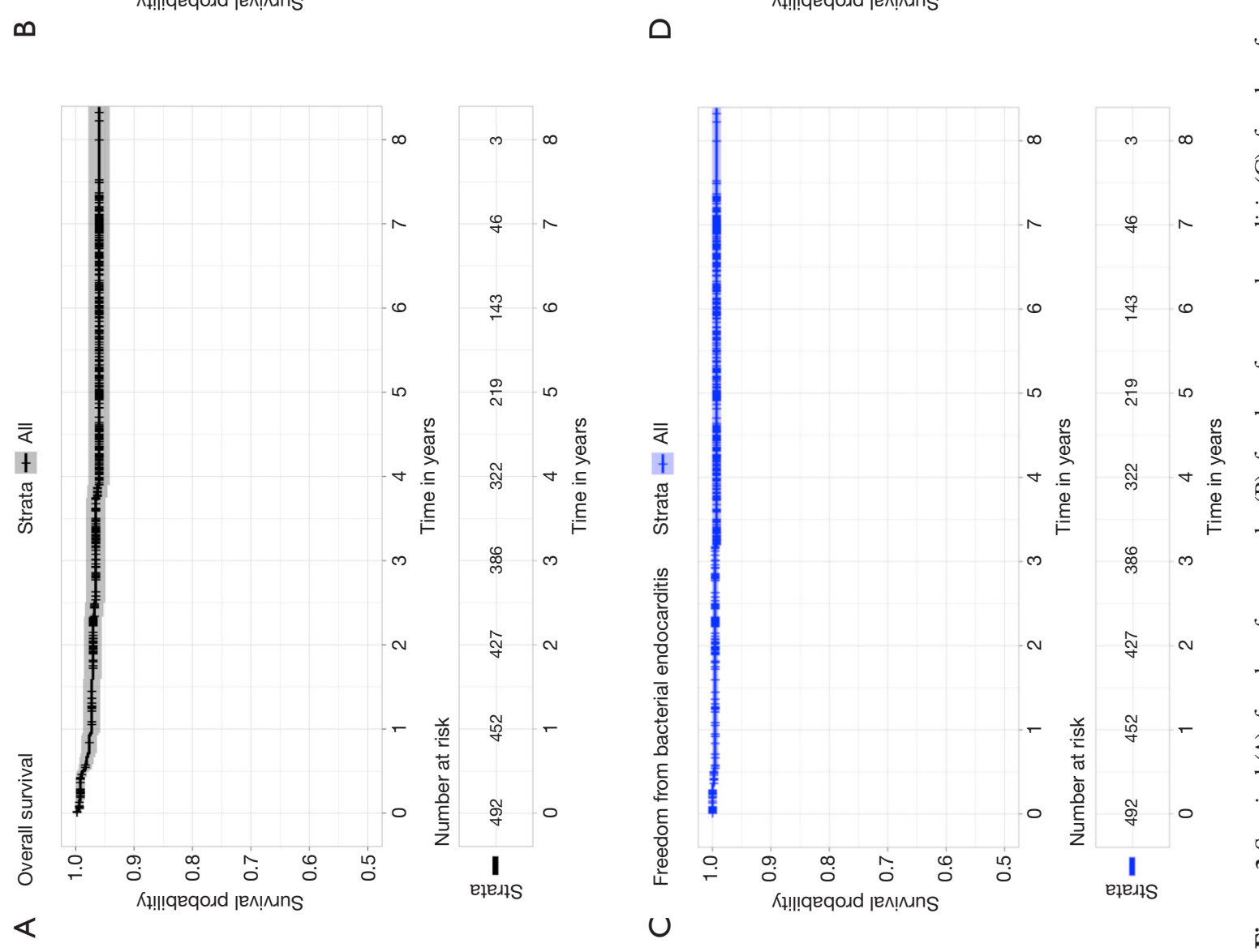

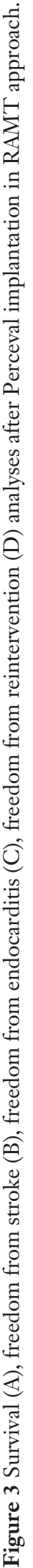

(C) Annals of Cardiothoracic Surgery. All rights reserved. Ann Cardiothorac Surg 2020;9(4):305-313 । http://dx.doi.org/10.21037/acs-2019-surd-172 


\begin{tabular}{|c|c|}
\hline Variables & Overall, $n=503$ \\
\hline \multicolumn{2}{|l|}{ At 30-day } \\
\hline Mortality, n (\%) & $4(0.8)$ \\
\hline Time to extubation, hours, mean \pm SD & $8.56 \pm 3.8$ \\
\hline Intensive care stay, days, mean \pm SD & $1.52 \pm 1.7$ \\
\hline Hospital stay, days, mean \pm SD & $6.4 \pm 3.8$ \\
\hline Revisions for bleeding, $\mathrm{n}(\%)$ & $1(0.2)$ \\
\hline Blood transfusion, $\mathrm{n}(\%)$ & $86(17.1)$ \\
\hline Stroke, n (\%) & $11(2.2)$ \\
\hline $\begin{array}{l}\text { Acute renal insufficiency }(\mathrm{CC}<85 \mathrm{~mL} / \mathrm{min}), \mathrm{n} \\
(\%)\end{array}$ & $7(1.3)$ \\
\hline Permanent pacemaker, n (\%) & $26(5.2)$ \\
\hline \multicolumn{2}{|l|}{ At follow-up } \\
\hline Survival & $96 \%$ \\
\hline Freedom for reoperation, (\%) & $499(99.2)$ \\
\hline NYHA class, mean \pm SD & $1.4 \pm 0.6$ \\
\hline Stroke, n (\%) & $4(0.8)$ \\
\hline Endocarditis, n (\%) & $3(0.6)$ \\
\hline Lung herniation, n (\%) & $4(0.8)$ \\
\hline Bioprosthesis degeneration, $\mathrm{n}(\%)$ & $4(0.8)$ \\
\hline
\end{tabular}

was $0.8 \%(4 / 503)$ and survival was $96 \%$ at follow-up (Figure $3 A$ ). We found three patients with moderate paravalvular leakage without hemolysis, not requiring any treatment. In the first phase of our experience, two patients had an incomplete expansion of the Perceval valve probably due to oversizing of the bioprosthesis, causing early moderate-severe paravalvular leakage which required reoperations at two and nine postoperative days. In our opinion, oversizing the prosthesis will not reduce the incidence of leakage; conversely, it might associate to incomplete expansion of the bioprosthesis with invagination of the annular Perceval portion (21). The potential advantages of the right minithoracotomy for AVR as well as the potential limitations and drawbacks of this technique have been recently reviewed (14). Especially when the ribs are not resected or disconnected from the sternum, this procedure may be very challenging because of the limited field and the difficult exposure of some regions of the aortic annulus; this is reflected by the longer operative and crossclamp times reported with this approach. A sutureless prostheses might represent a solution to this problem. Recently published studies comparing AVR through a right minithoracotomy versus a full sternotomy (22-28) report a longer $\mathrm{CPB}$ expressed as mean $\pm \mathrm{SD}$, minutes (range, $158 \pm 41$ to $99 \pm 23$ versus $107.1 \pm 32$ to $74 \pm 33$ ) and cross-clamp time (range, $107 \pm 26$ to $77 \pm 22$ versus $74 \pm 28$ to $44.8 \pm 13.4$ ). In our experience, Gilmanov et al. reported CPB and ACC times of 120 and 88 minutes in 133 patients who underwent AVR through a RAMT approach with sutured prosthesis implantation (28). With the introduction of sutureless bioprosthesis, $\mathrm{CPB}$ and ACC times were reduced to $81.6 \pm 30.8$ and $50.3 \pm 24.5$ minutes. Concomitant procedures were mitral valve surgery $(n=6)$, tricuspid valve repair $(n=1)$, mitral valve repair and tricuspid valve repair $(n=1)$ and myectomy $(\mathrm{n}=2)$. In patients with associated procedures, third intercostal space anterior minithoracotomy was preferred. The advantages of this technique include early mobilization and rehabilitation, less postoperative pain, excellent aesthetic results, and a lower incidence of wound complications (mediastinitis or osteomyelitis), especially in high-risk, obese, diabetic or osteoporotic patients. In our series, no vascular complications occurred and there was a lower incidence of postoperative stroke and AV block with subsequent pacemaker implant. These results from a large cohort of patients are very encouraging regarding the performance of the bioprosthesis and the surgical approach. We defined structural valve degeneration following the criteria established by Dvir et al. (29). At follow-up, Perceval degeneration occurred in four patients. We treated one patient with sutured bioprosthesis implantation and three patients with valve-in-valve procedure and transfemoral bioprosthesis implantation. We think that a degeneration rate of $0.8 \%$ for a biological prosthesis at mean follow-up of 4.6 years is very low, but we need long-term data to evaluate the real durability of this valve.

Some limitations exist in our report. This is a retrospective study. However, our series is reasonable if compared with other single center studies on the use of a sutureless prosthesis in a MIA. Patient selection for this type of device was left to the discretion of the surgeon. Another limitation is that we do not have the implantation time from the moment the aortic valve is excised to the moment the new valve is fully expanded. 


\begin{tabular}{|c|c|c|c|c|}
\hline LVEF (\%), mean \pm SD & $56.9 \pm 9.1$ & $55.3 \pm 7.3$ & $57.1 \pm 8.4$ & 0.47 \\
\hline Mean pressure gradient $(\mathrm{mmHg})$, mean $\pm \mathrm{SD}$ & $55.8 \pm 13.1$ & $14.6 \pm 8.1$ & $11.9 \pm 4.3$ & $<0.001$ \\
\hline LV mass, $\mathrm{g} / \mathrm{m}^{2}$ & 149.8 & & 113.6 & $<0.001$ \\
\hline LVES diameter $(\mathrm{mm})$, mean $\pm \mathrm{SD}$ & $31.7 \pm 6.9$ & & $27.8 \pm 6.5$ & $<0.001$ \\
\hline \multicolumn{5}{|l|}{ Paravalvular leakage, number of patients } \\
\hline Trivial & & 51 & 12 & \\
\hline Moderate & & 3 & 1 & \\
\hline
\end{tabular}

\section{Conclusions}

Our experience with the Perceval sutureless valve in a RAMT approach showed favorable clinical and hemodynamic results. Despite encouraging mid-term results, we need data documenting its long-term performance. Sutureless technology and its future evolutions, associated with MIA, might be considered as an alternative treatment option for AVR, especially in high-risk patients.

\section{Acknowledgments}

None.

\section{Footnote}

Conflicts of Interest: The authors have no conflicts of interest to declare.

Open Access Statement: This is an Open Access article distributed in accordance with the Creative Commons Attribution-NonCommercial-NoDerivs 4.0 International License (CC BY-NC-ND 4.0), which permits the noncommercial replication and distribution of the article with the strict proviso that no changes or edits are made and the original work is properly cited (including links to both the formal publication through the relevant DOI and the license). See: https://creativecommons.org/licenses/by-nc-nd/4.0/.

\section{References}

1. Nishimura RA, Otto CM, Bonow RO, et al 2017 AHA/ ACC Focused Update of the 2014 AHA/ACC Guideline for the Management of Patients With Valvular Heart
Disease: A Report of the American College of Cardiology/ American Heart Association Task Force on Clinical Practice Guidelines. Circulation 2017;135:e1159-95.

2. Goodney PP, O'Connor GT, Wennberg DE, et al. Do hospitals with low mortality rates in coronary artery bypass also perform well in valve replacement? Ann Thorac Surg 2003;76:1131-6; discussion 1136-7.

3. Brown JM, O'Brien SM, Wu C, et al. Isolated aortic valve replacement in North America comprising 108,687 patients in 10 years: changes in risks, valve types, and outcomes in the Society of Thoracic Surgeons National Database. J Thorac Cardiovasc Surg 2009;137:82-90.

4. Plass A, Scheffel H, Alkadhi H, et al. Aortic valve replacement through a minimally invasive approach: preoperative planning, surgical technique, and outcome. Ann Thorac Surg 2009;88:1851-6.

5. Shrestha M, Khaladj N, Bara C, et al. A staged approach towards interventional aortic valve implantation with a sutureless valve: initial human implants. Thorac Cardiovasc Surg 2008;56:398-400.

6. Shrestha M, Folliguet T, Meuris B, et al. Sutureless Perceval S aortic valve replacement: a multicenter, prospective pilot trial. J Heart Valve Dis 2009;18:698-702.

7. Schmitto JD, Mohr FW, Cohn LH. Minimally invasive aortic valve replacement: how does this perform in highrisk patients? Curr Opin Cardiol 2011;26:118-22.

8. Murtuza B, Pepper JR, Stanbridge RD, et al. Minimal access aortic valve replacement: is it worth it? Ann Thorac Surg 2008;85:1121-31.

9. Fischlein T, Meuris B, Hakim-Meibodi K, et al. CAVALIER Trial Investigators. The sutureless aortic valve at 1 year: A large multicenter cohort study. J Thorac Cardiovasc Surg 2016;151:1617-26.e4. 
10. Zannis K, Joffre J, Czitrom D, et al. Aortic valve replacement with the perceval S bioprosthesis: singlecenter experience in 143 patients. J Heart Valve Dis 2014;23:795-802.

11. Shrestha M, Fischlein T, Meuris B, et al. European multicentre experience with the sutureless Perceval valve: clinical and haemodynamic outcomes up to 5 years in over 700 patients. Eur J Cardiothorac Surg 2016;49:234-41.

12. Flameng $W$, Herregods MC, Hermans H, et al. Effect of sutureless implantation of the Perceval S aortic valve bioprosthesis on intraoperative and early postoperative outcomes. J Thorac Cardiovasc Surg 2011;142:1453-7.

13. Concistrè G, Chiaramonti F, Bianchi G, et al. Aortic Valve Replacement With Perceval Bioprosthesis: SingleCenter Experience With 617 Implants. Ann Thorac Surg 2018;105:40-6.

14. Glauber M, Miceli A, Bevilacqua S, et al. Minimally invasive aortic valve replacement via right anterior minithoracotomy: early outcomes and midterm follow-up. J Thorac Cardiovasc Surg 2011;142:1577-9.

15. Benetti FJ, Mariani MA, Rizzardi JL, et al. Minimally invasive aortic valve replacement. J Thorac Cardiovasc Surg 1997;113:806-7.

16. Cohn LH, Adams DH, Couper GS, et al. Minimally invasive cardiac valve surgery improves patient satisfaction while reducing costs of cardiac valve replacement and repair. Ann Surg 1997;226:421-6.

17. Bonacchi M, Prifti E, Giunti G, et al. Does ministernotomy improve postoperative outcome in aortic valve operation? A prospective randomized study. Ann Thorac Surg 2002;73:460-5.

18. Doll N, Borger MA, Hain J, et al. Minimal access aortic valve replacement: effects on morbidity and resource utilization. Ann Thorac Surg 2002;74:S1318-22.

19. Santana O, Reyna J, Grana R, et al. Outcomes of minimally invasive valve surgery versus standard sternotomy in obese patients undergoing isolated valve surgery. Ann Thorac Surg 2011;91:406-10.

Cite this article as: Solinas M, Bianchi G, Chiaramonti F, Margaryan R, Kallushi E, Gasbarri T, Santarelli F, Murzi M, Farneti P, Leone A, Simeoni S, Varone E, Marchi F, Glauber $M$, Concistrè G. Right anterior mini-thoracotomy and sutureless valves: the perfect marriage. Ann Cardiothorac Surg 2020;9(4):305-313. doi: 10.21037/acs-2019-surd-172
20. Merk DR, Lehmann S, Holzhey DM, et al. Minimal invasive aortic valve replacement surgery is associated with improved survival: a propensity-matched comparison. Eur J Cardiothorac Surg 2015;47:11-7; discussion 17.

21. Cerillo AG, Amoretti F, Mariani M, et al. Increased Gradients After Aortic Valve Replacement With the Perceval Valve: The Role of Oversizing. Ann Thorac Surg 2018;106:121-8.

22. Gilmanov D, Bevilacqua S, Murzi M, et al. Minimally invasive and conventional aortic valve replacement: a propensity score analysis. Ann Thorac Surg 2013;96:837-43.

23. Glauber M, Miceli A, Gilmanov D, et al. Right anterior minithoracotomy versus conventional aortic valve replacement: a propensity score matched study. J Thorac Cardiovasc Surg 2013;145:1222-6.

24. Mächler HE, Bergmann P, Anelli-Monti M, et al. Minimally invasive versus conventional aortic valve operations: a prospective study in 120 patients. Ann Thorac Surg 1999;67:1001-5.

25. Bakir I, Casselman FP, Wellens F. Minimally Invasive versus standard approach aortic valve replacement: a study in 506 patients. Ann THorac Surg 2006;81:1599-604.

26. Raja SG, Benedetto U, Amrani M. Aortic valve replacement through J-shaped partial upper sternotomy. J Thorac Dis 2013;5:S662-8.

27. de Vaumas C, Philip I, Daccache G, et al. Comparison of minithoracotomy and conventional sternotomy approaches for valve surgery. J Cardiothorac Vasc Anesth 2003;17:325-8.

28. Gilmanov D, Miceli A, Ferrarini M, et al. Aortic valve replacement through right anterior minithoracotomy: can sutureless technology improve clinical outcomes? Ann Thorac Surg 2014;98:1585-92.

29. Dvir D, Bourguignon T, Otto CM, et al. Standardized Definition of Structural Valve Degeneration for Surgical and Transcatheter Bioprosthetic Aortic Valves. Circulation 2018;137:388-99. 